\author{
UNIVERSIDADE DE SÃO PAULO \\ FACULDADE DE ODONTOLOGIA DE BAURU
}

\author{
CESAR BECALEL WAISBERG
}

Avaliação psicossocial e psicofísica de sujeitos com dor muscular mastigatória

BAURU 

CESAR BECALEL WAISBERG

\title{
Avaliação psicossocial e psicofísica de sujeitos com dor muscular mastigatória
}

\begin{abstract}
Dissertação apresentada a Faculdade de Odontologia de Bauru da Universidade de São Paulo para obtenção do título de Mestre em Ciências no Programa de Ciências Odontológicas Aplicadas, na área de concentração Biologia Oral.
\end{abstract}

Orientador: Prof. Dr. Leonardo Rigoldi Bonjardim

\section{Versão Corrigida}

\section{BAURU}


Becalel Waisberg, CESAR

Avaliação psicossocial e psicofísica de sujeitos com dor muscular mastigatória/ César Becalel Waisberg - Bauru, 2019. 62p. : il. ; $31 \mathrm{~cm}$.

Dissertação (Mestrado) - Faculdade de Odontologia de Bauru. Universidade de São Paulo

Orientador: Prof. Dr. Leonardo Rigoldi Bonjardim

Nota: A versão original desta dissertação encontra-se disponível no Serviço de Biblioteca e Documentação da Faculdade de Odontologia de Bauru - FOB/USP.

Autorizo, exclusivamente para fins acadêmicos e científicos, a reprodução total ou parcial desta dissertação, por processos fotocopiadores e outros meios eletrônicos.

Assinatura:

Data: $25 / 02 / 2019$

Comitê de Ética da FOB-USP

CAAE: 56439016.3.0000.5417

Data:17/08/2016 
FOLHA DE APROVAÇÃO 



\section{DEDICATÓRIA}

Dedico este trabalho a minha esposa Ariane David Waisberg pelo incentivo ao longo deste período e a minha filha Melissa David Waisberg, minha eterna motivação. 



\section{AGRADECIMENTOS}

Agradeço a FOB-USP na pessoa do seu diretor Prof. Dr. Carlos Ferreira dos Santos e ao chefe do departamento de Ciências Biológicas Prof. Dr. Rodrigo Cardoso de Oliveira.

Agradeço a CAPES, o presente trabalho foi realizado com apoio da Coordenação de Aperfeiçoamento de Pessoal de Nível Superior - Brasil (CAPES) Código de Financiamento 001.

Agradeço aos meus pais, Lia Waisberg e Fábio Muniz Waisberg (in memoriam), por todo esforço que sempre fizeram pela família.

Agradeço ao professor e amigo Paulo César Rodrigues Conti por todos os ensinamentos e pelas oportunidades que ajudou a abrir na área de Disfunções Temporomandibulares.

Agradeço ao colega de equipe Yuri Martins Costa por sua ajuda na finalização desta dissertação.

Agradeço ao meu orientador Leonardo Rigoldi Bonjardim por toda a paciência e dedicação para que este trabalho fosse finalizado. 



\section{RESUMO}

\section{Avaliação psicossocial e psicofísica de sujeitos com dor muscular mastigatória}

Objetivo: O objetivo deste estudo foi investigar alterações sensoriais mecânicas em tecido cutâneo sobre a musculatura mastigatória e cervical, assim como o nível de incapacidade cervical e de catastrofização dos indivíduos com DTM crônica de origem muscular e controles assintomáticos. Material e Métodos: Neste estudo transversal, 34 indivíduos do sexo feminino (Grupo DTM, $n=19$; Grupo Controle, $n=$ 15) foram examinados em sessão única por um examinador treinado e calibrado. Para o diagnóstico de DTM foi utilizado os critérios de diagnóstico do Diagnostic Criteria for Temporomandibular Disorders (DC/TMD, sigla em inglês). Os participantes também responderam aos questionários Neck Disability Index (NDI, sigla em inglês) e Escala de Catastrofização da dor (PCS, sigla em inglês) para avaliar o índice de incapacidade cervical e o nível de catastrofização relacionada à dor, respectivamente. Por fim, a avaliação somatossensorial mecânica cutânea foi realizada por meio dos testes de detecção mecânica (MDT, sigla em inglês) e limiar de dor mecânica (MPT, sigla em inglês) na porção superior do músculo trapézio e no corpo do músculo masseter. A análise dos resultados utilizou ANOVA com fator intrasujeito (sítio 2 níveis) e fator intersujeito grupo (2 níveis) para cada teste sensorial. Teste $T$ para amostras independentes foi usado para avaliar diferenças de idade, NDI e PCS entre os grupos. Por fim, a correlação de Pearson verificou a relação entre os valores de MPT entre os sítios musculares. Um nível de significância de $5 \%$ foi adotado. $\mathrm{Na}$ análise somatossensorial, para o MDT, o efeito principal foi a maior sensibilidade tátil no músculo masseter em relação ao trapézio $(F=28,5$ e $p<0,001)$, sem diferença entre os grupos. Os sujeitos do grupo DTM mostraram-se com maior sensibilidade dolorosa mecânica (MPT) em relação ao grupo controle $(F=5,41$ e $p=0,026)$, sem diferença entre os sítios musculares. Uma correlação positiva foi encontrada entre os valores de MPT dos músculos trapézio e masseter tanto dentro do grupo com DTM $(p<0,011)$ quanto daquelas assintomáticas $(p<0,001)$. Os valores do NDI $(p<0,001)$ e o PCS $(p=0,023)$ mostraram-se estatisticamente superiores nas pacientes com DTM. Conclui-se que as mulheres com DTM dolorosa associada à dor cervical apresentaram maior 

sensibilidade dolorosa cutânea em músculos trapézio e masseter e também maior grau de incapacidade cervical e de pensamentos catastróficos relacionados à dor.

Palavras-chave: Disfunção Temporomandibular, Incapacidade Cervical, Alterações Sensoriais, Catastrofização. 



\section{ABSTRACT \\ Psychosocial and psychophysical evaluation of subjects with masticatory muscular pain.}

Objective: The aim of this study was to investigate mechanical sensory changes in cutaneous tissues from masticatory and neck muscles, as well as neck disability and catastrophization levels in subjects with myogenous temporomandibular disorders and asymptomatic controls. Materials and Methods: In this cross-sectional study, 34 female subjects (TMD Group, $n=19$; Control Group, $n=15$ ) were assessed by a qualified examiner in a single session. The Diagnostic Criteria for Temporomandibular Disorders (DC/TMD) was used for the TMD diagnosis. All participants also filled the questionnaires Neck Disability Index (NDI) and Pain Catastrophization Scale (PCS) to evaluate neck disability and catastrophization related to pain levels, respectively. The mechanical somatosensory cutaneous analysis was performed through mechanical detection tests (MDT) and mechanical pain threshold (MPT) on the upper part of the trapezius and the body of the masseter. The analysis of the results used ANOVA with intra-rater factor (2 sites) and inter-rater group factor (2 levels) for each sensory test. T-Test for independent samples was performed to assess age differences, NDI and PCS between groups. Pearson correlation verified the MPT values relation between the muscles sites. It was adopted a significance level of $5 \%$. Concerning the somatosensory analysis, MDT showed as main effect a higher tactile sensitivity on the masseter when compared to the trapezius ( $F=28,5$ e $p<0,001)$, with no difference between groups. Subjects with TMD showed higher mechanical pain sensitivity (MPT) when compared to controls $(F=5,41$ e $p=0,026)$, with no difference between the muscle sites. A positive correlation was found between MPT values of trapezius and masseter in the TMD group $(p<0,011)$ as well as in the asymptomatic group $(p<0,001)$. NDI values $(p<0,001)$ and PCS $(p=0,023)$ were statistically higher in TMD patients. This study concluded that women with painful TMD associated with neck pain showed higher cutaneous pain sensitivity on the trapezius and masseter as well as higher neck disability and catastrophic thoughts related to pain.

Key-words: Temporomandibular Disorder, Neck Disability, Sensory Changes, Catastrophization. 



\section{LISTA DE TABELAS}

Tabela 1 - Tabela 1 - Média \pm desvio-padrão (DP) dos valores absolutos da idade, grau de incapacidade cervical (NDI, sigla em inglês) e de pensamentos catastróficos relacionados à dor nos grupos controle e DTM 



\section{LISTA DE FIGURAS}

Figura 1 - Análise de variância (ANOVA) com o fator intrasujeito sítio (2 níveis) e fator intersujeito grupo (2 níveis) dos valores transformados em $\log _{10}$ do limiar de detecção mecânica (MDT, sigla em inglês).

Figura 2 - Análise de variância (ANOVA) com o fator intrasujeito sítio (2 níveis) e fator intersujeito grupo (2 níveis) dos valores transformados em $\log _{10}$ do limar de dor mecânica (MPT, sigla em inglês)

Figura 3 - Correlação entre os valores transformados em $\log _{10}$ do MPT dos músculos trapézio e masseter dentro do grupo de mulheres com DTM.

Figura 4 - Correlação entre os valores transformados em $\log _{10}$ do MPT dos músculos trapézio e masseter dentro do grupo de mulheres assintomáticas. 



\section{LISTA DE ABREVIATURA E SIGLAS}

$\begin{array}{lll}\text { ANOVA } & \text { Análise de variância } \\ \text { DTM } & \text { Disfunção Temporomandibular } & \\ \text { DP } & \text { Desvio Padrão } \\ \text { MDT } & \text { Teste de Detecção Mecânica } & \text { (sigla em inglês) } \\ \text { MPT } & \text { Limiar de Dor Mecânica } & \text { (sigla em inglês) } \\ \text { NDI } & \text { Índice de incapacidade Cervical } & \text { (sigla em inglês) } \\ \text { PCS } & \text { Escala de catastrofização de dor (sigla em inglês) } \\ \text { PPT } & \text { Limiar de dor à pressão } & \text { (sigla em inglês) }\end{array}$





\section{SUMÁRIO}

1 INTRODUÇÃO 13

2 PROPOSIÇÃO 19

3 MATERIAL E MÉTODOS

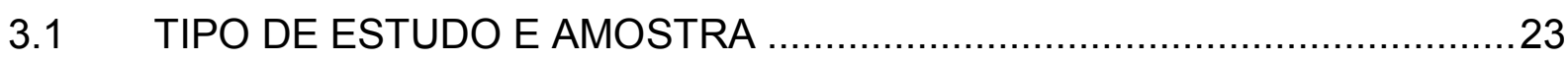

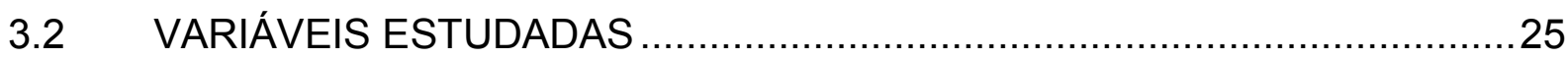

3.2.1 Questionários e Escalas Relacionados à Dor.........................................25

3.2.1.1 Índice de Incapacidade Cervical (Neck Disability Index - NDI, em inglês) (Anexo 3) 25

3.2.1.2 Escala de Pensamento Catastrófico sobre a Dor (PCS, sigla em inglês)

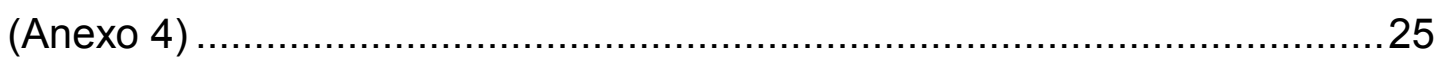

3.2.1.3 Avaliação Somatossensorial - Testes Quantitativos Sensoriais ..................26

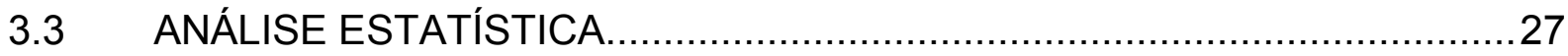

$4 \quad$ RESULTADOS

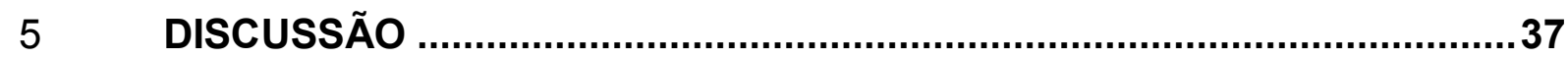

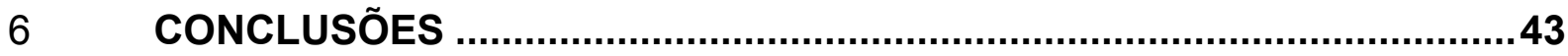

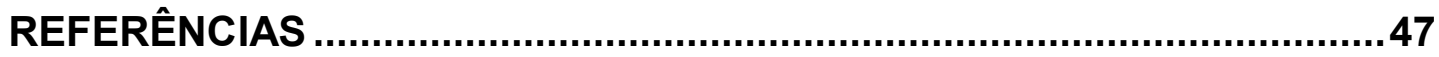

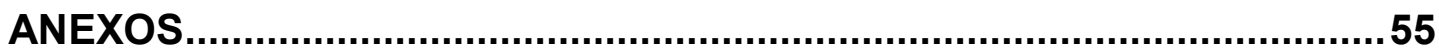





\section{INTRODUÇÃO E REVISÃO DA LITERATURA}





\section{INTRODUÇÃO E REVISÃO DA LITERATURA}

Dor é um fenômeno que pode ser percebido de diversas maneiras e, ao envolver aspectos neurofisiológicos, psicossociais, entre outros, possibilita que algo que seja dor para um indivíduo não represente dor para outro. Pode estar relacionada à idade, gênero, experiências prévias, mas, acima de tudo, é uma condição subjetiva e essencial para sobrevivência e proteção do organismo, mesmo que seja considerada uma experiência negativa. A dor representa um amplo campo de estudos, justamente por sua complexidade e subjetividade (MARCHAND, 2012).

As dores musculoesqueléticas, além de serem consideradas um problema de saúde pública, especialmente as crônicas, vem acompanhadas de redução na qualidade de vida, limitação nas atividades de vida diárias, incapacidades relacionadas ao trabalho e à atividades sociais (BLYTH et al., 2019). Dentre as dores musculoesqueléticas, a disfunção temporomandibular (DTM) estão atualmente entre as condições dolorosas mais comuns, impactando de modo significativo a qualidade de vida das pessoas afetadas (NATU et al., 2018).

A DTM representa um termo coletivo que envolve as patologias associadas à articulação temporomandibular, musculatura mastigatória ou ambas. São consideradas a principal causa de dores orofaciais não-odontogênicas (DE LEEUW; KLASSER, 2013), além de serem a principal causa de dores orofaciais crônicas. Um estudo recente, avaliou a prevalência de DTM por meio de critérios de diagnóstico atualizados em 2014 e mais aceitos atualmente (SCHIFFMAN et al., 2014) e verificou uma frequência de $26,7 \%$, sendo $16,3 \%$ dos diagnósticos relacionados a algum quadro de DTM dolorosa.

A DTM é considerada uma patologia de etiologia multifatorial e, por isso, ainda permanece difícil a identificação de uma causa direta, única e inquestionável. Além de sua multifatoriedade, pessoas com DTM normalmente reportam ou apresentam múltiplas comorbidades dolorosas (DAHAN et al., 2015; VISSCHER et al., 2015; COSTA et al., 2017a), destacando-se as dores de cabeça (MELO et al., 2010; COSTA et al., 2017b), a fibromialgia (FRAGA et al., 2012; GARCÍA-MOYA; 
MONTIEL-COMPANY; ALMERICH-SILLA, 2015) e a cervicalgia (DA COSTA et al., 2015; BRAGATTO et al., 2016).

A dor relacionada ao pescoço ou cervicalgia é um dos sinais e sintomas da disfunção da coluna cervical (DCC). As DCCs são condições comuns que afetam a região cervical e estruturas relacionadas. $\mathrm{Na}$ maioria das situações, são classificadas como inespecíficas e podem ter a presença ou ausência de sintomas irradiados para os ombros, braços, região interescapular e cabeça (ARMIJO-OLIVO et al., 2012).

Da mesma forma que a DTM, as DCCs são altamente prevalentes na população, assim uma associação entre ambas pode ser um achado comum. Tem sido observado que pacientes com DTM apresentam uma prevalência de DCC de variando de $23 \%$ à $70 \%$ (DE WIJER et al., 1996), enquanto na população sem DTM este número varia de $5 \%$ à $31 \%$ (VISSCHER et al., 2001).

Diversos estudos têm mostrado uma associação entre as DTM e a coluna cervical (DE FARIAS NETO et al., 2010; SILVEIRA et al., 2014; DA COSTA et al., 2015). A amplitude de movimento da coluna cervical foi encontrado estar diminuída em indivíduos com DTM quando comparados a sujeitos assintomáticos (GRONDIN et al., 2015). A presença de pontos-gatilho latentes se dá em maior quantidade em musculatura mastigatória (masseter) de pacientes com dor cervical crônica quando comparados aos assintomáticos (DE-LA-LLAVE-RINCON et al., 2012). Este mesmo estudo observou menor abertura bucal ativa no grupo com DTM. Quanto a presença de pontos sensíveis dolorosos, foram encontradas diferenças significativas entre indivíduos com DTM e DCC se comparado aos participantes saudáveis do grupo controle (SILVEIRA et al., 2014). Este mesmo estudo também mostrou que o limiar de dor em quase todos os músculos mastigatórios e cervicais era diminuído nos participantes com DTM e DCC se comparado aos participantes do grupo controle.

Quando a relação DTM e DCC foi investigada por aspectos de incapacidade, e não somente de sinais e sintomas, foi encontrado uma forte associação entre a DCC, mensurada por meio do questionário Índice de Incapacidade Cervical (NDI, sigla em inglês) e disfunção mandibular mensurada por meio da Escala Funcional Mandibular (JFS, sigla em inglês) (OLIVO et al., 2010). Associado a isso, um recente 
estudo do nosso grupo encontrou maiores níveis de incapacidade cervical (NDI) em pacientes com DTM (Da Costa et al., 2015).

Apesar de os sintomas das DCCs estarem frequentemente associados aos sintomas de mialgia em músculos da mastigação, ainda não há evidências robustas em que se demonstre uma relação de causa-efeito entre estas condições (STORM; WÄNMAN, 2006). Os sinais e sintomas das DCCs acompanham a severidade da DTM, mas o oposto não foi demonstrado (BEVILAQUA-GROSSI; CHAVES; DE OLIVEIRA, 2007). Este mesmo estudo sugeriu que, predominantemente, a DCC surge após a DTM, atuando como fator perpetuante, mais do que predisponente. Outro estudo apontou relação significante entre dor cervical e DTM, tornando-se a dor cervical mais acentuada com o aumento da severidade da DTM (CIANCAGLINI; TESTA; RADAELLI, 1999).

A relação entre a região orofacial e a coluna cervical tem sido explicada baseada nos aspectos neuroanatômicos e neurofisiológicos ( DE LAAT et al., 1998). As informações sensoriais da coluna cervical convergem com aferentes trigeminais no trato espinhal do núcleo trigeminal, já que as fibras que chegam ao subnúcleo caudal do trigêmeo estendem-se até C2-C3, ou mesmo até C6 (GREENBAUM et al., 2017). A distribuição sensorial dos nervos da cervical alta (raízes ventrais de C2-C3) também englobam parte da face, especialmente o ângulo da mandíbula (DE LAAT et al., 1998).

Uma das formas não-invasivas de se avaliar o sistema somatossensorial é por meio dos testes quantitativos sensoriais (QST, sigla em inglês) (ROLKE et al., 2006). Os QST são uma série de procedimentos que visam avaliar a sensibilidade mecânica, térmica e dolorosa. Por meio de testes mecânicos estáticos e dinâmicos podem-se analisar os limiares de percepção para estímulos inócuos ou nocivos, avaliar a somação temporal e a modulação dos impulsos nervosos, bem como detectar a presença de alodínia (SVENSSON et al., 2011).

Quantificar e qualificar essas alterações por meio dos QST pode ajudar a compreender melhor a relação dor/disfunção na musculatura do pescoço e na musculatura mastigatória, no entanto, para o nosso conhecimento nenhum estudo até o presente momento procurou avaliar a relação entre DTM e DCC por meio dos 
QST mecânicos, especialmente aqueles que mensuram limiares das aferências cutânea sobre a musculatura cervical e mastigatória. Além disso, pouco se tem sobre o impacto da DTM dolorosa de origem muscular associada à dor cervical nesses parâmetros sensoriais.

Além disso, o presente estudo investigou o nível de catastrofização, uma vez que pacientes com dor crônica costumam apresentar aspectos catastrofizantes quando mensurados por questionários específicos, sendo um deles a Escala de Catastrofização de Dor (PCS). Tais aspectos também contribuem fortemente para os processos de cronificação da dor e interferência na qualidade de vida (ALVAREZASTORGA et al., 2019). É, ainda, sugerido que tais alterações poderiam interferir também com resultados dos testes psicofísicos, como os de QST aqui testados (TAUB et al., 2017).

Baseado no acima descrito, a proposta deste estudo foi testar a hipótese nula de que não há diferenças na mensuração das funções somatossensoriais mecânicas cutâneas em musculatura mastigatória e cervical e grau de catastrofização em pacientes que apresentam DTM quando comparados a indivíduos assintomáticos. 
2 PROPOSIÇÃO 



\section{PROPOSIÇÃO}

O presente estudo teve como objetivo principal comparar o perfil somatossensorial mecânico cutâneo (doloroso ou não) nas musculaturas da região do pescoço (trapézio) e da região orofacial (masseter) em mulheres com DTM e dor na região cervical de origem muscular e controles assintomáticas. Adicionalmente, o grau de incapacidade cervical e o nível de catastrofização relacionado à dor também foram comparados entre os grupos acima referidos. 

3 MATERIAL E MÉTOdOS 



\section{MATERIAL E MÉTODOS}

\subsection{Tipo de Estudo e Amostra}

Tratou-se de um estudo do tipo caso controle e de corte transversal que foi iniciado após aprovação pelo Comitê de Ética em Pesquisa com Seres Humanos da Faculdade de Odontologia de Bauru - Universidade de São Paulo (CAAE: 56439016.3.0000.5417 - Anexo 1). Para participar da pesquisa, todos os sujeitos assinaram voluntariamente o Termo de Consentimento Livre e Esclarecido (TCLE), de acordo com as normas referido Comitê de Ética (Anexo 2).

A amostra de voluntárias com Disfunção Temporomandibular foi selecionada na Clínica de Dor Orofacial do Instituto de Ensino Odontológico de Bauru (IEO) e a partir do setor de triagem da Faculdade de Odontologia de Bauru (FOB-USP) e foi composta de indivíduos do gênero feminino. Já a amostra de mulheres assintomáticas foi pareada por idade e foi obtida a partir de voluntárias da comunidade da FOB-USP. As participantes foram convidadas a participar voluntariamente da pesquisa e foram recrutadas através de cartazes expostos no IEO, no campus da FOB-USP, no setor de Triagem da FOB-USP.

A partir disso, foram constituídos dois grupos: O grupo com DTM (GRUPO 1) foi composto por 19 indivíduos que apresentaram DTM primariamente do tipo muscular, conforme classificação do Diagnostic Criteria for Temporomandibular Disorders (DC-TMD, sigla em inglês) (SCHIFFMAN et al., 2014) e incluíram de maneira resumida os seguintes critérios:

1- História positiva de dor na mandíbula, têmpora ou região da orelha no último mês; MAIS

2- Dor modificada com a movimentação, função ou parafunção

3- Relato de dor familiar à palpação do masseter ou temporal (com ou sem espalhamento) OU durante abertura máxima assistida ou não. 
Adicionalmente, os sujeitos deste grupo deveriam apresentar queixa de dor na região cervical e foi considerado para posterior avaliação somatossensorial na região do pescoço o músculo trapézio em sua porção superior entre a sétima vértebra cervical (C7) e acrômio.

O grupo de controles assintomáticas (Grupo 2) foi constituído por 15 mulheres sem diagnóstico de DTM e livres de qualquer queixa e/ou diagnóstico de outra condição dolorosa orofacial e cervical.

Todos as mulheres do estudo foram previamente avaliadas por profissionais especializados em DTM e dor orofacial da Faculdade de Odontologia de Bauru.

Foram considerados aptos a participar deste estudo os indivíduos de ambos os gêneros, com faixa etária entre 20 e 50 anos, que apresentassem DTM primariamente do tipo muscular há pelo menos 3 meses determinando um caráter crônico da doença, além de um grupo controle composto por indivíduos sem qualquer queixa de dor na face e/ou no pescoço e pareados por sexo e idade em relação ao grupo com DTM. Ressalta-se aqui que o grupo com DTM acabou sendo composto apenas por mulheres e, por consequência o grupo controle também, o que vai de encontro à maior prevalência dessa disfunção no gênero feminino. Os critérios de exclusão para todos os participantes da pesquisa foram: artralgia, alterações neuropáticas ou que apresentam diagnóstico de cefaleia primária, fibromialgia, artrite reumatoide, lúpus eritematoso e outras doenças sistêmicas não controladas. Ainda, indivíduos em uso contínuo de medicamentos antidepressivos, ansiolítico, bem como medicação com glicocorticoides foram excluídos. Por fim, aqueles que utilizaram medicação analgésica, anti-inflamatórios não esteroidais (AINES) e opiódes, em até 24 horas antes da avaliação também foram considerados inaptos para participação deste estudo.

Esses critérios de exclusão foram escolhidos para controlar os possíveis efeitos de patologias físicas e mentais, bem como o uso de medicação nas variáveis que foram estudadas. 


\subsection{Variáveis de Estudo}

Após a inclusão das voluntárias na amostra, as seguintes variáveis foram mensuradas em uma única sessão:

\subsubsection{Questionários e Escalas Relacionados à Dor}

\subsubsection{1 Índice de Incapacidade Cervical (Neck Disability Index - NDI, em} inglês) (Anexo 3)

O grau de incapacidade cervical e a dor região do pescoço foram mensurados pelo questionário NDI, inicialmente desenvolvido em 1991 (VERNON; MIOR, 1991). Sua tradução, adaptação e validação para a língua portuguesa do Brasil foi realizada por Cook et al., 2006. Este instrumento de auto-relato é composto por 10 seções e cada sessão possui 6 possibilidades de respostas que se referem a uma atividade de vida diária, com exceção da questão cinco, sobre cefaleia. As alternativas descrevem graus crescentes do impacto da dor/disfunção cervical sobre as atividades realizadas, considerado 0 nenhuma incapacidade e 5 grau máximo de incapacidade. No total, o escore do NDI refere-se à soma dos pontos das seções e pode perfazer até 50 pontos. Assim, escores mais altos implicam maior incapacidade. A interpretação da pontuação de incapacidade foi: 0-4 = nenhuma; 514 = leve; 15 a 24 = moderado; 25-34 = grave; mais de 34 = incapacidade completa (Cook et al., 2006).

\subsubsection{Escala de Pensamento Catastrófico sobre a Dor (PCS, sigla em} inglês) (Anexo 4)

Esse questionário de autopreenchimento mensura pensamentos catastróficos relacionados à dor. É composta por 13 afirmações que aborda três componentes distintos: ruminação, magnificação e desesperança. Em suma, esta escala indica a frequência com que cada um dos pensamentos ou sentimentos ocorrem no momento em que o individuo vivencia a sua dor. Cada afirmação varia em uma

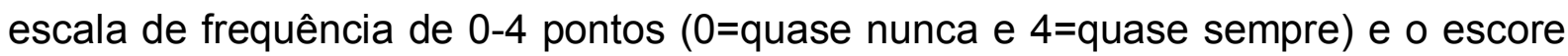
final e a pontuação total é calculada pela soma de todos os itens, que varia de 0 a 
52 pontos. Assim, quanto maior o escore, maior o grau de catastrofização. Os estudos indicam que a PCS apresenta alto consistência interna e está associada à elevada severidade da dor e probabilidade reduzida de retorno ao trabalho (Sehn et al., 2012). A versão validada e traduzida para o português brasileiro foi utilizada (Sehn et al., 2012).

\subsubsection{Avaliação Somatossensorial - Testes Quantitativos Sensoriais}

Após a avaliação clínica e aplicação dos questionários, foi realizada a determinação do perfil somatossensorial mecânico cutâneo (doloroso ou não) na musculatura cervical (porção superior do músculo trapézio) e mastigatória (corpo do masseter) através de uma sequência de dois testes sensoriais da bateria germânica de QST (ROLKE et al., 2006).

Limiar de Detecção Mecânica (MDT, sigla inglês) (Anexo 5)

Este teste consta da utilização de um kit de 20 monofilamentos de nylon calibrados e de diferentes diâmetros adaptados por Semmes-Weinstein para determinação do limiar tátil dos pacientes. Esses monofilamentos exercem forças específicas que aumentam conforme também aumenta o calibre do monofilamento $\left(0,008 \mathrm{~g} / \mathrm{mm}^{2}\right.$ até $\left.300 \mathrm{~g} / \mathrm{mm}^{2}\right)$. Cada monofilamento foi aplicado perpendicularmente na pele sobre a região a ser avaliada (trapézio e corpo do masseter) com uma leve pressão até o mesmo se curvar.

A participante foi instruída a fechar os olhos e a relatar verbalmente quando sentisse um "leve toque" na área de contato dos monofilamentos. Os testes iniciaram com o filamento menos calibroso $\left(0,008 \mathrm{~g} / \mathrm{mm}^{2}\right)$ e foram aplicados sequencialmente filamentos cada vez mais calibrosos até que a participante reportasse verbalmente sentir um leve toque como instruído no início teste, o que foi considerado como um estímulo positivo. Após esse relato positivo, inverteu-se a ordem e seguiu-se para o próximo filamento com valor mais baixo, até que a participante não sentisse mais a aplicação do estímulo tátil. Isso foi considerado como um estímulo negativo. Essa medição foi feita até se obter cinco estímulos negativos (descendentes) e cinco estímulos positivos (ascendentes) e a média 
geométrica dessas repetições foi considerada o MDT (ROLKE et al., 2006; SVENSSON et al., 2011).

- Limiar de Sensibilidade Dolorosa Mecânica (MPT, sigla em inglês) (Anexo 5)

Este teste consta também da utilização de monofilamentos adaptados por Semmes-Weinstein em calibres de ordem crescente, objetivando saber qual é o filamento de menor diâmetro que a participante da pesquisa reportou uma sensação dolorosa correspondente a uma "agulhada, alfinetada, picada". Anteriormente ao teste, a participante foi instruída a fechar os olhos e a relatar verbalmente quando a sensação de toque do monofilamento se transformasse em dor.

Da mesma forma que para o MDT, cada monofilamento foi aplicado perpendicularmente na pele sobre a região a ser avaliada (trapézio e corpo do masseter) com uma leve pressão até o mesmo se curvar. A participante foi instruída a fechar os olhos e a relatar verbalmente quando sentisse dor na área de contato dos monofilamentos. Os testes também iniciaram com o filamento menos calibroso e foram aplicados sequencialmente filamentos cada vez mais calibrosos até que a participante reportasse verbalmente sentir DOR como instruído no início do teste, o que foi considerado como um estímulo positivo. Após esse relato positivo, inverteuse a ordem e seguiu-se para o próximo filamento com valor mais baixo, até que a participante não sentisse mais a sensação dolorosa. Isso foi considerado como um estímulo negativo. Essa medição foi feita até se obter cinco estímulos negativos (descendentes) e cinco estímulos positivos (ascendentes) e a média geométrica dessas repetições foi considerada o MPT (ROLKE et al., 2006; SVENSSON et al., 2011).

\subsection{ANÁLISE ESTATÍSTICA}

Os dados foram preferencialmente descritos por meio da média e \pm desviopadrão (DP). Além disso, as variáveis quantitativas foram avaliadas por meio do teste de Kolmogorov-Smirnov para verificar o pressuposto de distribuição gaussiana dos dados considerando um nível de significância de $5 \%$. Nos casos em que esse 
pressuposto não foi observado, uma transformação logarítmica na base 10 foi aplicada e obteve-se uma normalidade secundária. Assim, as seguintes variáveis foram transformadas previamente às análises inferenciais: MDT e MPT.

Uma modelo de análise de variância (ANOVA) considerando o fator intrasujeito sítio (2 níveis) e fator intersujeito grupo (2 níveis) foi aplicado para comparar diferenças nas variáveis somatossensoriais. Já o teste post-hoc de Tukey foi utilizado para as análises de comparações múltiplas. Já o teste t para amostras independentes foi utilizado para avaliar diferenças de idade, incapacidade cervical e catastrofização da dor entre os grupos. Por fim, o teste de correlação de Pearson foi usado para verificar a relação do MPT entre os dois sítios musculares. O nível de significância estabelecido foi de $5 \%(p=0,050)$. 
4 Resultados 



\section{RESULTADOS}

Trinta e quatro mulheres foram recrutadas e divididas em dois grupos de acordo com a presença de DTM e dor cervical. No grupo DTM a média de idade foi de $33,42 \pm 7,96$ e no grupo de controles assintomáticas de $31,67 \pm 6,84$, sem diferenças significativas entre os grupos $(p=0,502)$. Adicionalmente, o grupo de mulheres com DTM apresentaram maiores escores de incapacidade cervical (NDI, $p<0,001)$ e também mais pensamentos catastróficos relacionados à dor (PCS, $p=0,023)$ em relação às controles (Tabela 1 ).

Tabela 1 -Média \pm desvio-padrão (DP) dos valores absolutos da idade, grau de incapacidade cervical (NDI, sigla em inglês) e de pensamentos catastróficos relacionados à dor nos grupos controle e DTM.

\begin{tabular}{lccc}
\hline Variáveis & Controle & DTM & Valor de P \\
\hline Idade & $31,67 \pm 6,84$ & $33,42 \pm 7,96$ & $\mathrm{p}=0,502$ \\
NDI & $4,07 \pm 2,46$ & $8,95 \pm 3,98$ & $\mathrm{p}<0,001$ \\
PCS & $12,33 \pm 10,23$ & $20,74 \pm 10,19$ & $\mathrm{p}=0,023$ \\
\hline
\end{tabular}

* teste t para amostras independentes

Na sequência são apresentados os resultados da comparação dos dois testes sensoriais (MDT - Figura 1 e MPT - Figura 2) entre os grupos, avaliando-se também o efeito principal e uma possível interação com os sítios musculares (masseter e trapézio).

Na figura 1 está apresentado um efeito principal do sítio muscular para o limiar de detecção mecânica (MDT, sigla em inglês), o que indica que este parâmetro modificou os limiares mecânicos de maneira significativa, sendo que os valores do MDT para o músculo trapézio foram maiores em relação ao masseter ( $F=$ 28,5 e $p<0,001$ ). Porém, não houve efeito principal significante do grupo (DTM e controle) para o MDT $(F=0,155$ e $p=0,69)$. 


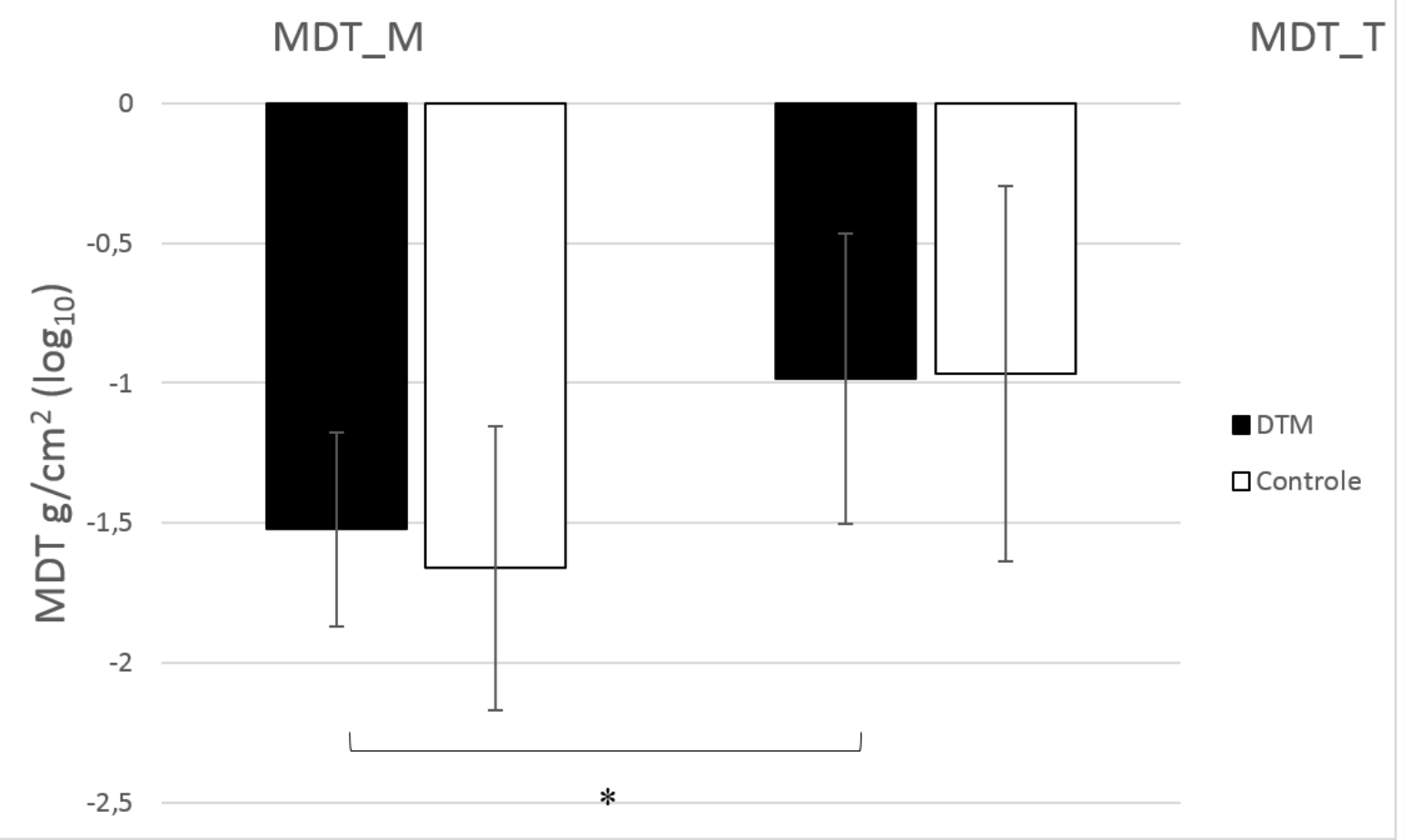

Figura 1 - Análise de variância (ANOVA) com o fator intrasujeito sítio (2 níveis) e fator intersujeito grupo (2 níveis) dos valores transformados em $\log _{10}$ do limiar de detecção mecânica (MDT, sigla em inglês). MPT_M= limiar de dor mecânica do masseter; MPT_T= limiar de dor mecânica do trapézio

* indica diferença significativa entre sítios musculares $(F=28,5$ e $p<0,001)$, independente de grupo DTM e controle assintomática.

Um efeito principal do grupo para o limiar de dor mecânica (MPT, sigla em inglês) foi observado (Figura 2), o que indica que este parâmetro modificou os limiares dolorosos de maneira significativa, sendo que os valores do MPT das participantes do grupo com DTM foram menores em relação às mulheres assintomáticas $(F=5,41$ e $p<0,026)$, mas não ocorreu um efeito principal significante do sítio muscular (trapézio e masseter) nos valores do MPT ( $F=0,14$ e $p=0,70)$. 


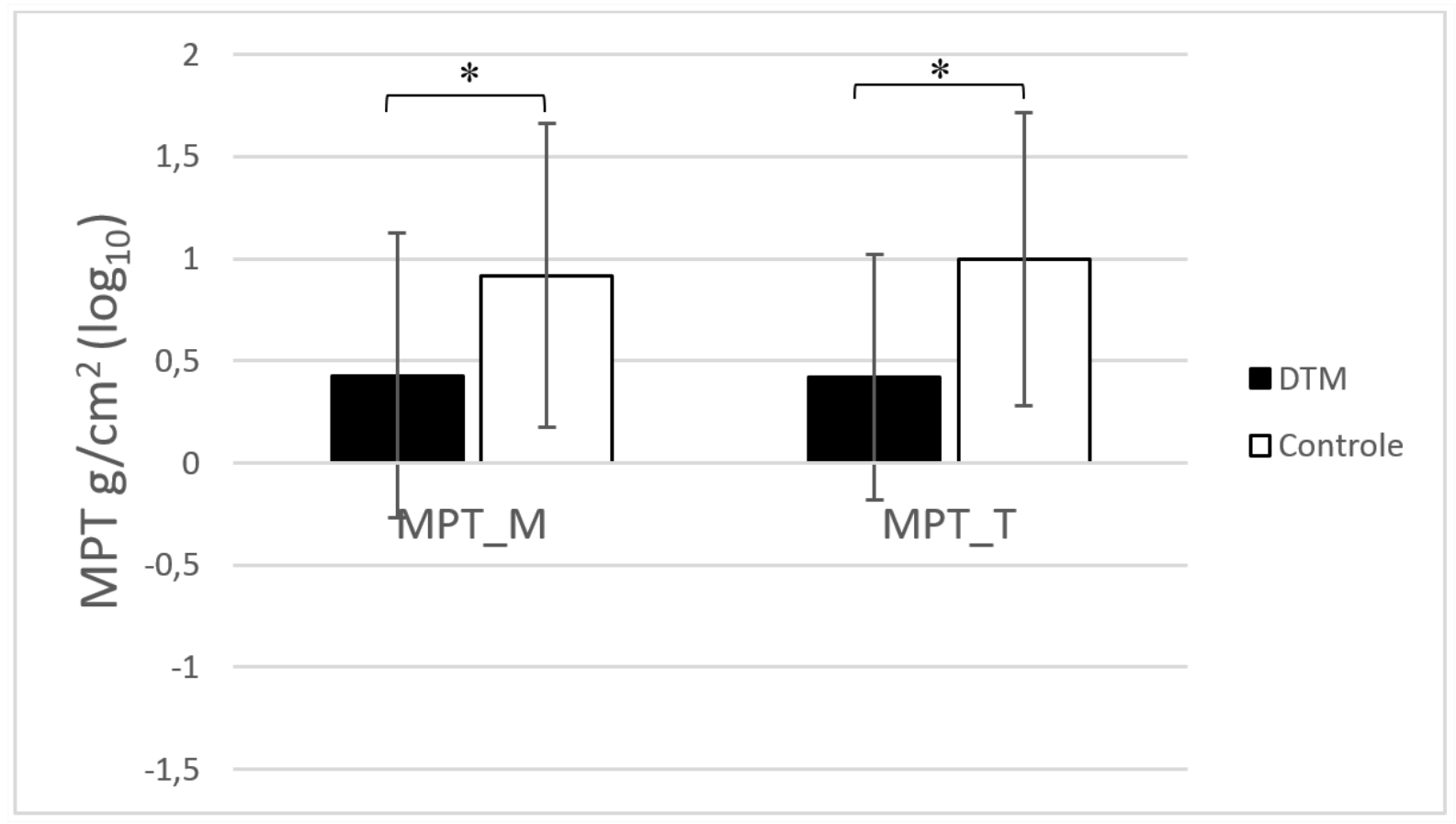

Figura 2 - Análise de variância (ANOVA) com o fator intrasujeito sítio (2 níveis) e fator intersujeito grupo (2 níveis) dos valores transformados em $\log _{10}$ do limar de dor mecânica (MPT, sigla em inglês). MPT_M= limiar de dor mecânica do masseter; MPT_T= limiar de dor mecânica do trapézio

* indica diferença significativa entre os grupos $(F=5,41$ e $p<0,026)$, independente do sítio muscular.

O teste de correlação de Pearson encontrou uma correlação positiva significativa entre os valores de MPT dos músculos trapézio e masseter para ambos os grupos (Figuras 3 e 4), ou seja, independente da presença de dor nos segmentos cervical e da face (Grupo DTM, $p=0,011$; Grupo Controle, $p<0,001$ ). 


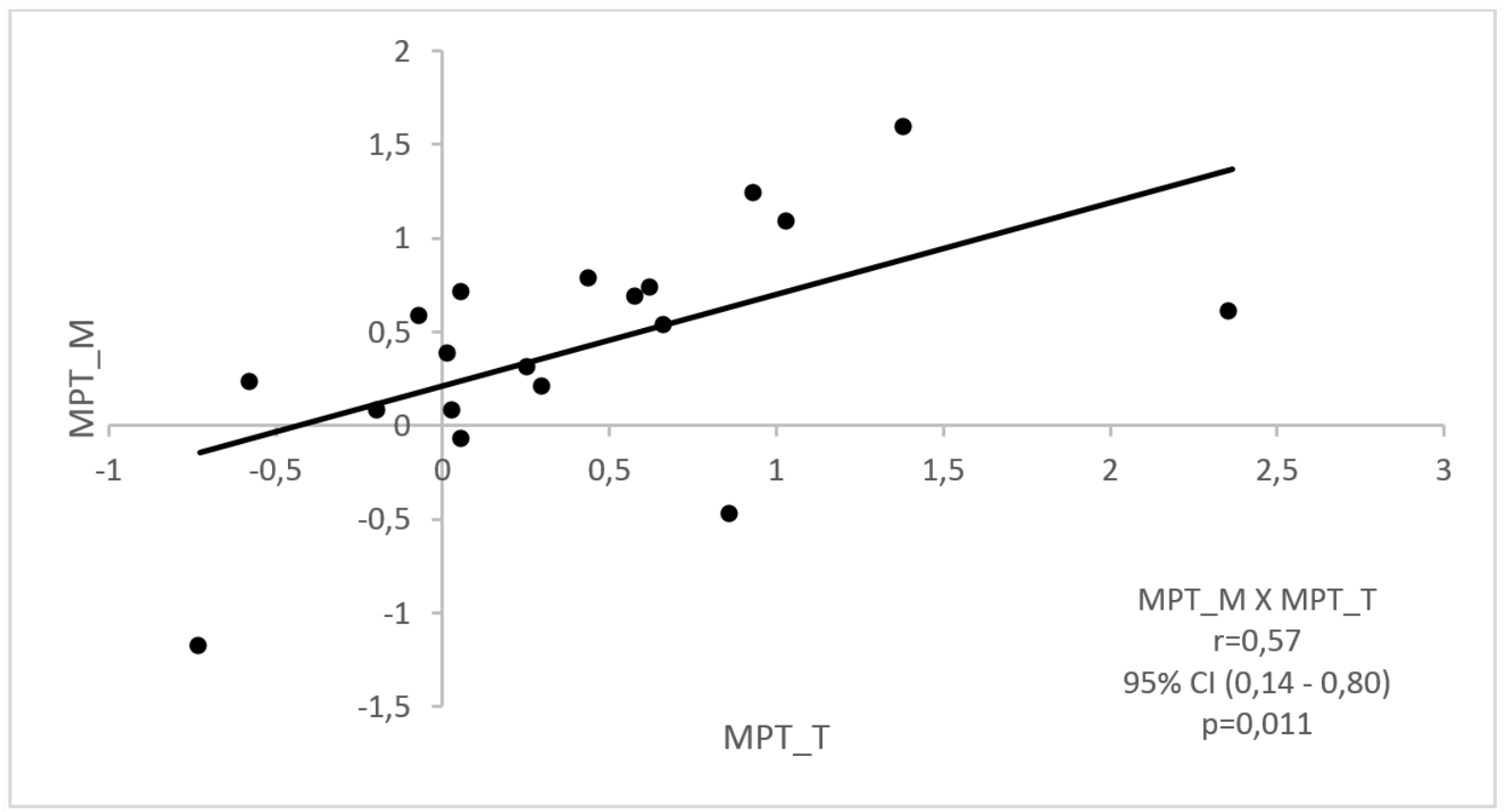

Figura 3 - Correlação entre os valores transformados em $\log _{10}$ do MPT dos músculos trapézio e masseter dentro do grupo de mulheres com DTM.

* MPT_M= limiar de dor mecânica do masseter; MPT_T= limiar de dor mecânica do trapézio

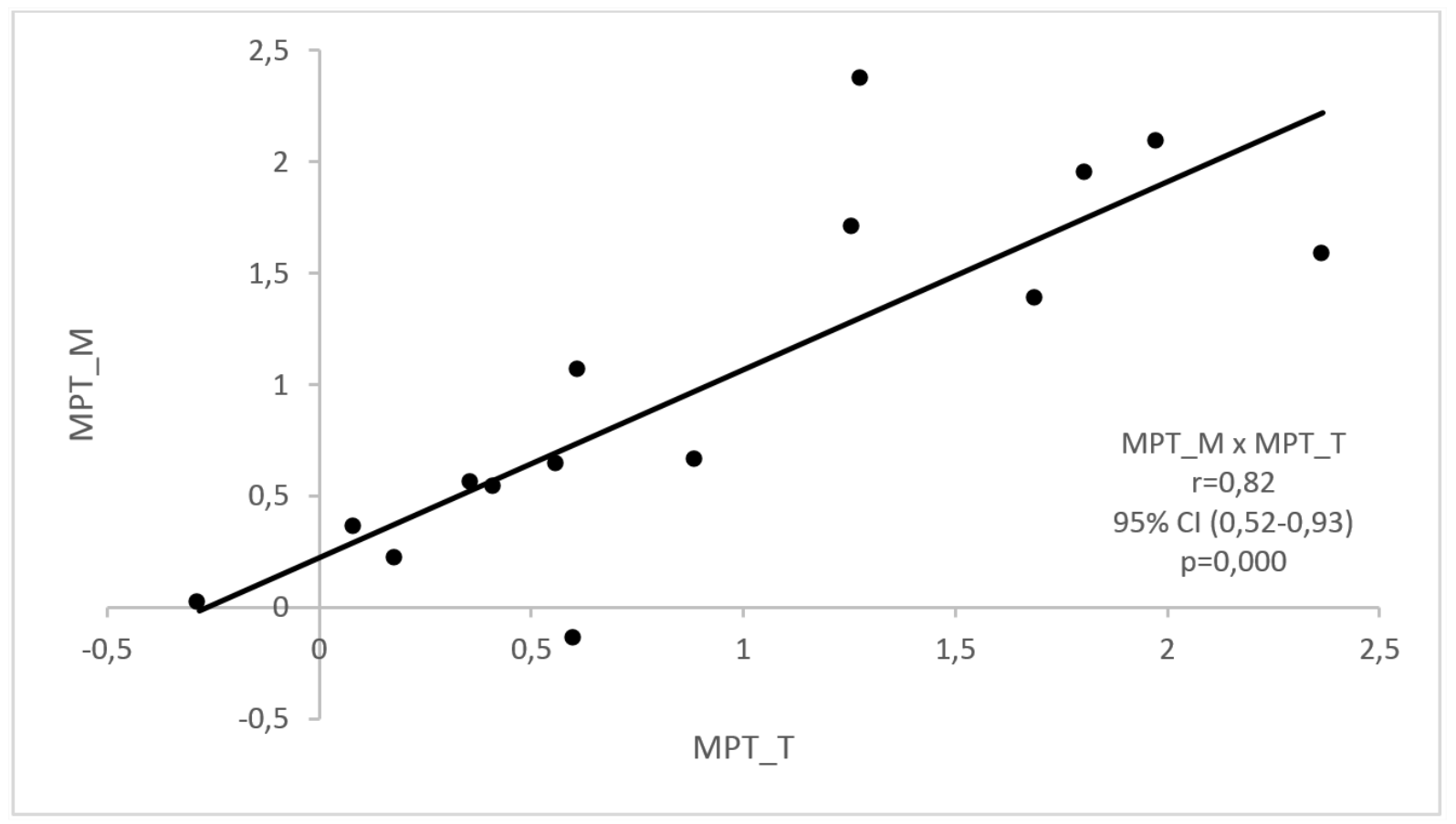

Figura 4 - Correlação entre os valores transformados em $\log _{10}$ do MPT dos músculos trapézio e masseter dentro do grupo de mulheres assintomáticas.

*MPT_M= limiar de dor mecânica do masseter; MPT_T= limiar de dor mecânica do trapézio 
5 DISCUSSÃO 



\section{DISCUSSÃO}

O presente estudo teve como objetivo principal comparar o perfil somatossensorial mecânico cutâneo (doloroso ou não) nas musculaturas da região do pescoço (trapézio) e da região orofacial (masseter) em mulheres com DTM e dor na região cervical de origem muscular e controles assintomáticas. Adicionalmente, o grau de incapacidade cervical e o nível de catastrofização relacionado à dor também foram comparados entre os grupos acima referidos. Como principais achados podemos citar: 1- Os limiares de detecção mecânica (MDT) se apresentaram maiores no músculo trapézio em relação ao músculo masseter, sem diferença entre os grupos; 2- O limiar de dor mecânica (MPT) se mostrou menor no grupo de mulheres com DTM em relação àquelas do grupo controle, sem diferença entre os sítios musculares; 3- Uma correlação positiva entre o MPT de trapézio e masseter foi observada dentro de cada grupo; 4- O grau de incapacidade cervical e o nível de pensamentos catastróficos foi maior no grupo de mulheres com DTM.

Em suma, a avaliação dos limiares sensoriais fornece um método psicofísico para examinar a função das fibras nervosas periféricas e suas conexões no Sistema Nervoso Central, tendo os testes quantitativos sensoriais o objetivo de quantificar a magnitude da estimulação necessária para produzir uma sensação em particular (ROLKE et al., 2006). Assim, no presente estudo podemos indicar que o músculo masseter se mostrou mais sensível ao toque (MDT) do que o músculo trapézio, independente da presença de DTM dolorosa e incapacidade e dor cervical. Ainda, foi verificada uma maior sensibilidade à dor em tecido cutâneo entre os grupos, independente do sítio muscular de aplicação do MPT.

O grupo de mulheres com DTM dolorosa e queixa de dor na região cervical superior apresentou limiar tátil semelhante ao grupo de controles assintomáticas, ou seja, a presença de dor nos referidos segmentos não interferiu nesse parâmetro somatossensorial. Um estudo prévio, utilizando-se de um teste de acuidade tátil, o limiar de discriminação entre dois pontos, também não encontrou diferença estatisticamente significativa nesse limiar entre pacientes com dor leve e recorrente no pescoço e controles saudáveis quando este foi aplicado no segundo (C2) e 
sétimo (C7) segmentos cervicais (ELSIG et al., 2014). Em contrapartida, como esperado, o músculo masseter apresentou maior sensibilidade tátil do que 0 trapézio. Sabe-se que a sensibilidade tátil varia normalmente ao longo dos diferentes segmentos do nosso corpo e está principalmente relacionada a fatores periféricos, isto é, a densidade de fibras nervosas aferentes e o tipo de receptores específicos (BESNE et al., 2002; YANG et al., 2014). Assim, o achado em relação ao MDT pode ser atribuído ao fato de que o número de fibras nervosas epidérmicas nas áreas faciais é significativamente maior do que nos membros e no tronco (BESNE et al., 2002).

Com relação ao MPT, os resultados demonstraram uma maior sensibilidade dolorosa em mulheres do grupo DTM dolorosa crônica associada à dor na região do pescoço em relação àquelas controles assintomáticas, independente do sítio muscular. De maneira geral, a maioria dos estudos lança mão de um teste sensorial que avalia dor em tecido profundo, no caso o limiar de dor à pressão (PPT, sigla em inglês), o qual tem se demonstrado menor em pacientes com DTM em relação aos controles, tanto quando aplicado na musculatura mastigatória, quanto cervical (SILVEIRA et al., 2014; DA COSTA et al., 2015). Estudos de caso controle em amostras com DTM verificaram em musculatura mastigatória e ATM, a presença de menores valores de MPT em relação aos controles (KOTHARI et al., 2015; HILGENBERG-SYDNEY; KOWACS; CONTI, 2016). No entanto, para nosso conhecimento, não há estudos que se utilizam do MPT para avaliar diferenças entre pacientes com DTM e controles, considerando a presença de queixa de dor na região cervical associada ao diagnóstico de DTM dolorosa. Assim, nossos achados indicam a importância das aferências cutâneas nociceptivas nos quadros de dores que acometem tecidos mais profundos, como as diagnosticadas no presente estudo.

Além dessa maior sensibilidade cutânea em musculatura mastigatória e cervical nos pacientes com DTM, foi também encontrada uma maior incapacidade cervical nesse mesmo grupo, em sua maioria de grau leve. Esses resultados corroboram estudos anteriores (OLIVO et al., 2010; DA COSTA et al., 2015) e reforçam o conceito de comorbidade entre DTM e dor / disfunção cervical (KRAUS, 2007; COSTA et al., 2017a). Esta relação apresenta relevância clínica, uma vez que o paciente com DTM associada à incapacidade cervical deve ter o diagnóstico e o 
tratamento focado nas duas regiões, já que a reabilitação em uma área poderá influenciar diretamente a outra.

$\mathrm{Na}$ avaliação do pensamento catastrófico sobre a dor, o grupo de mulheres com DTM apresentou maiores índices de catastrofização quando comparados àquelas do grupo controle. Estes achados podem indicar um quadro mais labiríntico da dor orofacial, uma vez que tem sido evidenciado que em pacientes com nível moderado a severo de DTM, os pensamentos catastróficos sobre a dor representam um papel importante nas funcionalidades físicas e psicossociais (TURNER et al., 2001). Adicionalmente, dentre os pacientes com DTM, aqueles que apresentaram elevados níveis de catastrofização aumentaram as chances de dor persistente e também contribuíram para sua cronificação, especialmente nos casos de dores miofasciais (REITER et al., 2018)

Em suma, a proximidade anatômica, interconexões neuronais e baseado em evidências sobre a convergência neurofisiológica de impulsos sensoriais de neurônios nociceptivos e não-nociceptivos cervicais na região do subnúcleo caudal do sistema trigeminal associada a alta prevalência de DTM e incapacidade cervical na população, tornam esse estudo de grande relevância, bem como seus achados. Baseado nisso, podemos sugerir algumas implicações clínicas deste estudo. A relação de comorbidade entre DTM e Incapacidade cervical parece ser real e pode ser explicada pelos seguintes mecanismos: (1) convergência neuronal das regiões trigeminal e cervical (MORCH et al., 2007); (2) processos de sensibilização central (WOOLF, 2011); e (3) comprometimento do sistema endógeno inibitório descendente da dor (OSSIPOV et al., 2014). Portanto o reconhecimento de ambas condições dolorosas é fundamental no prognóstico de pacientes com DTM, bem como uma pode ser fator de risco para o desenvolvimento da outra ou ainda ser importante na manutenção da dor.

Algumas limitações deste estudo devem ser observadas. Primeiro, apesar da significância dos nossos resultados, a amostra foi pequena, considerando a natureza transversal do estudo. Uma segunda limitação é a não utilização da bateria completa dos testes quantitativos sensoriais, o que poderia nos trazer uma avaliação mais completa de diferentes fibras aferentes sensoriais. Assim, mais generalizações deste estudo devem ser feitas com cuidado. 

6 CONCLUSÕES 



\section{CONCLUSÕES}

Os resultados do presente estudo permitem concluir que as mulheres com DTM dolorosa associada à dor na região cervical apresentam maior sensibilidade dolorosa cutânea em músculos trapézio e masseter e também maior grau de incapacidade cervical e de pensamentos catastróficos relacionados à dor. 

REFERÊNCIAS 



\section{REFERÊNCIAS}

ALRASHDAN, M.S.; NUSEIR, A.; AL-OMIRI, M.K. Prevalence and correlations of temporomandibular disorders in Northern Jordan using diagnostic criteria axis I. J Investig Clin Dent, v. 20, e12390, 2019.

ALVAREZ-ASTORGA, A. et al. Pain catastrophising in a population of patients with migraine. Neurologia, pii: S0213-4853(19)30015-5, 2019.

ARMIJO-OLIVO, S. et al. Patients with temporomandibular disorders have increased fatigability of the cervical extensor muscles. Clin J Pain, v. 28, n. 1, p. 55-64, 2012.

BESNE'. I.; DESCOMBES, C.; BRETON L. Effect of age and anatomical site on density of sensory innervation in human epidermis. Arch Dermatol, v. 138, p.14451450, 2002.

BEVILAQUA-GROSSI, D.; CHAVES, T.C.; OLIVEIRA A.S. Cervical spine signs and symptoms: perpetuating rather than predisposing factors for temporomandibular disorders in women. J Appl Oral Sci, v. 15, n. 4, p. 259-264, 2007.

BLYTH, F.M. et al. The Global Burden of Musculoskeletal Pain-Where to From Here? Am J Public Health, v. 109, n. 1, p. 35-40, 2019.

BRAGATTO, M.M. et al. Associations among temporomandibular disorders, chronic neck pain and neck pain disability in computer office workers: a pilot study. J Oral Rehabil, v. 43, n. 5, p. 321-322, 2016.

CIANCAGLINI, R.; TESTA, M.; RADAELLI, G. Association of neck pain with symptoms of temporomandibular dysfunction in the general adult population. Scand J Rehabil Med, v. 31, n. 1, p. 17-22, 1999.

COOK, C. et al. Cross-cultural adaptation and validation of the Brazilian Portuguese version of the Neck Disability Index and Neck Pain and Disability Scale. Spine (Phila, PA, 1976), v. 31, n. 14, p. 1621-1627, 2006.

COSTA, Y.M. et al. Headache Exacerbates Pain Characteristics in Temporomandibular Disorders. J Oral Facial Pain Headache, v. 31, n. 4, p. 339$345,2017 b$. 
COSTA, Y.M. et al. Temporomandibular disorders and painful comorbidities: clinical association and underlying mechanisms. Oral Surg Oral Med Oral Pathol Oral Radiol, v. 123, n. 3, 288-297, 2017a.

DA COSTA, D.R. et al. Neck disability is associated with masticatory myofascial pain and regional muscle sensitivity. Arch Oral Biol, v. 60, n. 5, p. 745-752, 2015.

DAHAN, $H$. et al. Specific and number of comorbidities are associated with increased levels of temporomandibular pain intensity and duration. J Headache Pain, v. 16, p. 528, 2015.

DE FARIAS NETO, J.P. et al. Radiographic measurement of the cervical spine in patients with temporomandibular dysfunction. Arch Oral Biol, v. 55, n. 9, p. 670-678, 2010.

DE LAAT, A. et al. Correlation between cervical spine and temporomandibular disorders. Clin Oral Investig, v. 2, n. 2, p. 54-57, 1998.

DE LEEUW, R; KLASSER, G.D. Orofacial Pain: Guidelines for Assessment, Diagnosis and Management. Hannover Park: Quintessence Publishing Co; 2013.

DE WIJER, A. et al. Temporomandibular and cervical spine disorders. Self-reported signs and symptoms. Spine, v., n. 14, p. 1638-1646, 1996.

DE-LA-LLAVE-RINCON, A.I. et al. Myofascial trigger points in the masticatory muscles in patients with and without chronic mechanical neck pain. J Manipulative Physiol Ther, v. 35, n. 9, p. 678-684, 2012.

ELSIG, S. et al. Sensorimotor tests, such as movement control and laterality judgment accuracy, in persons with recurrent neck pain and controls. A case-control study. Man Ther, v. 19, n. 6, 555-561, 2014.

FRAGA, B.P. et al. Signs and symptoms of temporomandibular dysfunction in fibromyalgic patients. J Craniofac Surg, v. 23n. 2, p. 615-618.

GARCÍA-MOYA, E.J.; MONTIEL-COMPANY, J.M.; ALMERICH-SILLA, J.M. Casecontrol study of craniomandibular disorders in patients with fibromyalgia. J Clin Exp Dent, v. 7, n.2, p. e293-298, 2015.

GREENBAUM, T. et al. Cervical flexion-rotation test and physiological range of motion - A comparative study of patients with myogenic temporomandibular disorder versus healthy subjects. Musculoskelet Sci Pract, v. 27, p. 7-13, 2017. 
GRONDIN, F. et al. Upper cervical range of motion is impaired in patients with temporomandibular disorders. Cranio, v. 33, n. 2, p. 91-99, 2015.

HILGENBERG-SYDNEY, P.B.; KOWACS, P.A.; CONTI, P.C. Somatosensory evaluation in Dysfunctional Syndrome patients. J Oral Rehabil, v. 43, n. 2, p. 89-95, 2016.

KOTHARI, S.F. et al. Somatosensory assessment and conditioned pain modulation in temporomandibular disorders pain patients. Pain, v. 156, n. 12, p. 2545-2455, 2015.

KRAUS, S. Temporomandibular disorders, head and orofacial pain: cervical spine considerations. Dent Clin North Am, v. 51, n. 1, p. 161-193, 2007.

MARCHAND, W.R. Mindfulness-based stress reduction, mindfulness-based cognitive therapy, and Zen meditation for depression, anxiety, pain, and psychological distress. J Psychiatr Pract, 2012 Jul;18(4):233-52.

MELO, C.E. et al. Temporomandibular disorders dysfunction in headache patients. Med Oral Patol Oral Cir Bucal, v. 17, n. 6, p. e1042-1046.

MORCH, C.D. et al. Convergence of cutaneous, musculoskeletal, dural and visceral afferents onto nociceptive neurons in the first cervical dorsal horn. Eur $\mathbf{J}$ Neurosci, v. 26 , p. 142-154, 2007.

NATU, V.P. et al. Temporomandibular disorder symptoms and their association with quality of life, emotional states and sleep quality in South-East Asian youths. J Oral Rehabil, v. 45, n. 10, p. 756-763, 2018.

OLIVO, S.A. et al. The association between neck disability and jaw disability. J Oral Rehabil, v. 37, n. 9, p. 670-679, 2010.

OSSIPOV, M.H.; MORIMURA, K.; PORRECA, F. Descending pain modulation and chronification of pain. Curr Opin Support Palliat Care, v. 8, p. 143-151, 2014.

REITER, S. et al. Pain Catastrophizing and Pain Persistence in Temporomandibular Disorder Patients. J Oral Facial Pain Headache, v. 32, n. 3, p. 309-320, 2018.

ROLKE, R. et al. Quantitative sensory testing in the German Research Network on Neuropathic Pain (DFNS): standardized protocol and reference values. Pain, v. 123, n. 3, p. 231-243, 2006. 
SCHIFFMAN, E. et al. Diagnostic Criteria for Temporomandibular Disorders (DC/TMD) for Clinical and Research Applications: recommendations of the International RDC/TMD Consortium Network ${ }^{*}$ and Orofacial Pain Special Interest Groupt. J Oral Facial Pain Headache, v. 28, n. 1, p. 6-27, 2014.

SEHN, F. et al. Cross-cultural adaptation and validation of the Brazilian Portuguese version of the pain catastrophizing scale. Pain Med, v. 13, p. 1425-1435, 2012.

SILVEIRA, A. et al. Masticatory and cervical muscle tenderness and pain sensitivity in a remote area in subjects with a temporomandibular disorder and neck disability. $\mathbf{J}$ Oral Facial Pain Headache, v. 28, n.2, p. 138-146, 2014.

STORM, C.; WANMAN, A. Temporomandibular disorders, headaches, and cervical pain among females in a Sami population. Acta Odontol Scand, v. 64, n. 5, p. 319325, 2006.

SVENSSON, P. et al. Guidelines and recommendations for assessment of somatosensory function in oro-facial pain conditions - a taskforce report. $\mathbf{J}$ Oral Rehabil. v. 38, n. 5, p. 366-94, 2011.

TAUB, C.J. et al. Effects of a Pain Catastrophizing Induction on Sensory Testing in Women with Chronic Low Back Pain: A Pilot Study. Pain Res Manag, 2017:7892494, 2017.

TURNER, J.A. et al. The roles of beliefs, catastrophizing, and coping in the functioning of patients with temporomandibular disorders. Pain, v. 92, n. 1-2, p. 4151, 2001.

VERNON H, MIOR S. The Neck Disability Index: a study of reliability and validity. J Manipulative Physiol Ther, v. 14, n. 7, p. 409-415, 1991.

VISSCHER, C.M. et al. Comorbid disorders and sociodemographic variables in temporomandibular pain in the general Dutch population. $\mathbf{J}$ Oral Facial Pain Headache, v. 29, n. 1, p. 51-59, 2015.

VISSCHER, C.M. et al. Prevalence of cervical spinal pain in craniomandibular pain patients. Eur J Oral Sci, v. 109, n. 2, p. 76-80, 2001.

WOOLF, C.J. Central sensitization: implications for the diagnosis and treatment of pain. Pain, v. 152, p. S2-S15, 2011. 
YANG, G. et al. A study on variability of quantitative sensory testing in healthy participants and painful temporomandibular disorder patients. Somatosens Mot Res., v. 31, n. 2, p. 62-71, 2014. 

AnEXOS 

ANEXO 1 - Parecer do comitê de ética

\section{FACULDADE DE ODONTOLOGIA DE BAURU- USP}

\section{PARECER CONSUBSTANCIADO DO CEP}

\section{DADOS DO PROJETO DE PESQUISA}

Título da Pesquisa: Avaliação psicossocial e psicofísica de sujeitos com dor muscular mastigatória.

Pesquisador: Cesar B. Waisberg

Área Temática:

Versão: 2

CAAE: 56439016.3 .0000 .5417

Instituição Proponente: Universidade de Saq Paulo

Patrocinador Principal: Financiamento Próprio

\section{DADOS DO PARECER}

Número do Parecer: 1.704.027

\section{Apresentação do Projeto:}

Idem ao parecer consubstanciado $\mathrm{n}^{\circ}$ 1.595.789, emitido em 16.6.2016.

\section{Objetivo da Pesquisa:}

Idem ao parecer consubstanciado $\mathrm{n}^{\circ}$ 1.595.789, emitido em 16.6.2016.

\section{Avaliação dos Riscos e Benefícios:}

Idem ao parecer consubstanciado $\mathrm{n}^{\circ}$ 1.595.789, emitido em 16.6.2016.

Comentários e Considerações sobre a Pesquisa:

Idem ao parecer consubstanciado $\mathrm{n}^{\circ}$ 1.595.789, emitido em 16.6.2016.

Considerações sobre os Termos de apresentação obrigatória:

Idem ao parecer consubstanciado $\mathrm{n}^{\circ}$ 1.595.789, emitido em 16.6.2016.

Conclusões ou Pendências e Lista de Inadequações:

As pendências apontadas no parecer consubstanciado $n^{\circ} 1.595 .789$, de 16.6.2016 foram devidamente atendidas, de forma que sou favorável à aprovação desse estudo.

Considerações Finais a critério do CEP:

Esse projeto foi considerado APROVADO na reunião ordinária do CEP de 17.08.2016, com base nas normas éticas da Resolução CNS 466/12. Ao término da pesquisa o CEP-FOB/USP exige a apresentação de relatório final. Os relatórios parciais deverão estar de acordo com o cronograma

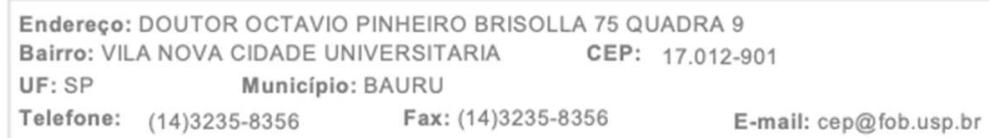




\section{FACULDADE DE ODONTOLOGIA DE BAURU- USP}

Continuação do Parecer: 1.704.027

e/ou parecer emitido pelo CEP. Alterações na metodologia, título, inclusão ou exclusão de autores, cronograma e quaisquer outras mudanças que sejam significativas deverão ser previamente comunicadas a este CEP sob risco de não aprovação do relatório final. Quando da apresentação deste, deverão ser incluídos todos os TCLLES e/ou termos de doação assinados e rubricados, se pertinentes.

\#Este parecer foi elaborado baseado nos documentos abaixo relacionados:

\begin{tabular}{|c|c|c|c|c|}
\hline Tipo Documento & Arquivo & Rostagem & Autor & Situação \\
\hline $\begin{array}{l}\text { Informações Básicas } \\
\text { do Projeto }\end{array}$ & $\begin{array}{l}\text { PB_INFORMAÇŐES_BASICAS_DO_P } \\
\text { ROJETO_612445.pdf }\end{array}$ & $\begin{array}{c}01 / 07 / 2016 \\
12: 47: 45 \\
\end{array}$ & & Aceito \\
\hline Outros & Carta_CEP.pdf & $\begin{array}{c}01 / 07 / 2016 \\
12: 46: 29\end{array}$ & Cesar B. Waisbera & Aceito \\
\hline $\begin{array}{l}\text { Projeto Detalhado I } \\
\text { Brochura } \\
\text { Investigador }\end{array}$ & Projeto_mestrado_Cesar.docx & $\begin{array}{c}29 / 06 / 2016 \\
15: 27: 23\end{array}$ & Cesar B. Waisbera & Aceito \\
\hline Outros & Aquiescencia_IEO.pdf & $\begin{array}{c}29 / 06 / 2016 \\
15: 22: 47\end{array}$ & Cesar B. Waisbera & Aceito \\
\hline $\begin{array}{l}\text { TCLE / Termos de } \\
\text { Assentimento / } \\
\text { Justificativa de } \\
\text { Ausência }\end{array}$ & TCLE.pdf & $\begin{array}{c}18 / 05 / 2016 \\
10: 45: 14\end{array}$ & Cesar B. Waisbera & Aceito \\
\hline Outros & Questionario_tecnico.pdf & $\begin{array}{l}18 / 05 / 2016 \\
10: 06: 52\end{array}$ & Cesar B. Waisberg & Aceito \\
\hline \begin{tabular}{|l|} 
Declaração de \\
Instituição e \\
Infraestrutura \\
\end{tabular} & Carta_de_encaminhamento.pdf & $\begin{array}{c}28 / 04 / 2016 \\
19: 03: 33\end{array}$ & Cesar B. Waisbera & Aceito \\
\hline $\begin{array}{l}\text { Declaração de } \\
\text { Pesquisadores }\end{array}$ & Declaracao_pesquisador.pdf & $\begin{array}{c}28 / 04 / 2016 \\
19: 02: 10 \\
\end{array}$ & Cesar B. Waisbera & Aceito \\
\hline Folha de Rosto & 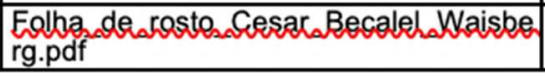 & $\begin{array}{c}28 / 04 / 2016 \\
18: 48: 42 \\
\end{array}$ & Cesar B. Waisbera & Aceito \\
\hline
\end{tabular}

Situação do Parecer:

Aprovado

Necessita Apreciação da CONEP:

Não

BAURU, 30 de Agosto de 2016

\section{Assínado por: \\ Izabel Regina Eiscber Rubira Bullen \\ (Coordenador)}

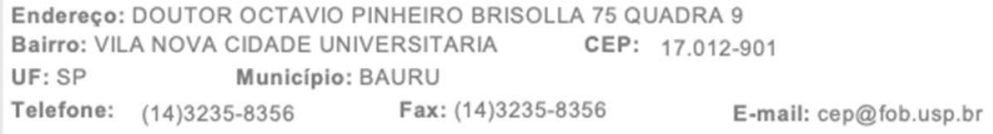




\section{ANEXO 2 \\ Universidade de São Paulo
Faculdade de Odontologia de Bauru \\ Pág. 1 de 2}

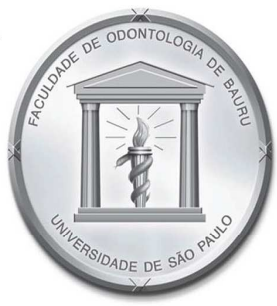

Departamento de Ciências Biológicas

\section{TERMO DE CONSENTIMENTO LIVRE E ESCLARECIDO}

O Sr/Sra. está sendo convidado a participar da pesquisa "Avaliação Psicossocial e Psicofísica de Sujeitos com Dor Muscular Mastigatória" com orientação do Professor Leonardo Rigoldi Bonjardim. Esta pesquisa tem por objetivo investigar as alterações sensoriais em musculatura mastigatória e cervical, assim como o nível de incapacidade cervical e de catastrofização dos indivíduos com Disfunção Temporomandudibular crônica de origem muscular. Para tanto, você passará por avaliações que constarão de questionários, exames físicos e testes de sensibilidade. Os testes de sensibilidade serão realizados por meio da aplicação de estímulos em músculos da face, cabeça, pescoço e das costas, para que possamos avaliar sua percepção de tato, e de dor. Para todos os exames serão utilizados equipamentos amplamente seguros. No entanto, há de se considerar um risco mínimo e algum desconforto durante realização dos testes de sensibilidade. A avaliação do Sr./Sra. com esta sequência de testes e exames pode ser benéfica, pois podemos diagnosticar algum tipo de alteração neurológica e/ou muscular. Uma vez diagnosticada alguma destas alterações, você será encaminhado para a triagem e, de acordo com a demanda, para a Clínica de Disfunção Temporomandibular dessa própria instituição. Todos os exames serão realizados em apenas uma sessão e terão a duração média de uma hora. Nenhuma dessas avaliações trará qualquer tipo de dano físico (podendo haver apenas um pequeno desconforto relacionado ao teste de sensibilidade como relatado anteriormente), moral ou material para o Sr/Sra. As informações fornecidas serão mantidas confidenciais, respeitando sua privacidade. Os resultados obtidos serão analisados e publicados em meios de informação científica, sem a sua identificação, de qualquer forma. O Sr/Sra. não terá nenhum gasto ou ganho financeiro por participar na pesquisa, e também não correrá risco algum além de um leve incomodo proveniente dos testes realizados, bem como não haverá qualquer ressarcimento. Você é livre para deixar de participar a qualquer momento sem nenhum prejuízo. Caso não concorde em participar desta pesquisa, sua vontade será respeitada, seu nome será preservado e você não será penalizado física ou psicologicamente por isso, pois não é de nosso interesse causar constrangimentos ou danos à sua imagem. Ainda, o Sr/Sra. terá garantia de indenização diante de eventuais danos decorrentes da pesquisa. Declaro ainda, que jamais será exigido dos participantes da pesquisa, sob qualquer argumento, renúncia ao direito à indenização por dano. Uma via deste Termo de Consentimento Livre e Esclarecido ficará com você e outra conosco. Qualquer dúvida a respeito da pesquisa poderá entrar em contato com o aluno/pesquisador César Becalel Waisberg, Fone: (14) 98111-2011, e-mail: cesar@waisberg.com.br. 
ANEXO 3

\section{Índice de Incapacidade Relacionada ao Pescoço (Neck Disability Index)}

Este questionário foi criado para dar informações sobre como a sua dor no pescoço tem afetado a sua habilidade para fazer atividades diárias. Por favor responda a cada uma das perguntas e marque em cada seção apenas uma alternativa que melhor se aplique a você.

Seção 1 - Intensidade da dor

- $\quad \square$ Eu não tenho dor neste momento.

- $\quad$ A dor é muito leve neste momento.

- $\quad$ A dor é moderada neste momento.

- $\quad$ A dor é razoavelmente grande neste momento.

- $\quad \square$ A dor é muito grande neste momento.

- $\quad$ A dor é a pior que se possa imaginar neste momento.

Seção 2 - Cuidados pessoais (se lavar, se vestir, etc.)

- $\quad$ Eu posso cuidar de mim mesmo (a) sem aumentar a dor.

- $\quad$ Eu posso cuidar de mim mesmo (a) normalmente, mas isso faz aumentar a dor.

- $\square$ É doloroso ter que cuidar de mim mesmo e eu faço isso lentamente e com cuidado.

- $\quad$ Eu preciso de ajuda mas consigo fazer a maior parte do meu cuidado pessoal.

- $\quad$ Eu preciso de ajuda todos os dias na maioria os aspectos relacionados a cuidar de mim mesmo (a).

- $\quad$ Eu não me visto, me lavo com dificuldade e fico na cama.

Seção 3 - Levantar coisas

- $\quad$ Eu posso levantar objetos pesados sem aumentar a dor.

- $\quad$ Eu posso levantar objetos pesados mas isso faz aumentar a dor.

- $\quad$ A dor me impede de levantar objetos pesados do chão, mas eu consigo se estiverem colocados em uma boa posição, como por exemplo em uma mesa.

- $\quad$ A dor me impede de levantar objetos pesados, mas consigo levantar objetos com peso entre leve e médio, se estiverem colocados em uma boa posição.

- $\quad$ Eu posso levantar objetos muito leves.

- $\quad$ Eu não posso levantar nem carregar absolutamente nada.

Seção 4 - Leitura

- $\quad \square$ Eu posso ler tanto quanto eu queira sem dor no meu pescoço.

- $\quad$ Eu posso ler tanto quanto eu queira com uma dor leve no pescoço. 
- $\quad$ Eu posso ler tanto quanto eu queira com uma dor moderada no pescoço.

- $\square$ Não posso ler tanto quanto eu queira por causa de uma dor moderada no meu pescoço.

- $\square$ Eu mal posso ler por causa de uma grande dor no meu pescoço.

- $\quad$ Eu não posso ler nada.

Seção 5 - Dores de cabeça

- $\quad$ Eu não tenho nenhuma dor de cabeça.

- $\square$ Eu tenho pequenas dores de cabeça com pouca frequência.

- $\square$ Eu tenho dores de cabeça moderadas com pouca frequência

- $\square$ Eu tenho dores de cabeça moderadas muito frequentemente

- $\square$ Eu tenho dores de cabeça fortes frequentemente.

- $\square$ Eu tenho dores de cabeça quase o tempo inteiro.

Seção 6 - Prestar atenção

$\square$ Eu consigo prestar atenção quando eu quero sem dificuldade.

$\square$ Eu consigo prestar atenção quando eu quero com uma dificuldade leve.

$\square$ Eu tenho uma dificuldade em prestar atenção quando eu quero.

$\square$ Eu tenho muita dificuldade em prestar atenção quando eu quero.

口 Eu tenho muitíssima dificuldade em prestar atenção quando eu quero.

$\square$ Eu não consigo prestar atenção.

Seção 7 - Trabalho

$\square$ Eu posso trabalhar tanto quanto eu quiser.

口 Eu só consigo fazer o trabalho que estou acostumado (a), mas nada além disso.

$\square$ Eu consigo fazer a maior parte do trabalho que estou acostumado (a), mas nada além disso.

$\square$ Eu não consigo fazer o trabalho que estou acostumado (a) a fazer.

$\square$ Eu mal consigo fazer qualquer tipo de trabalho.

$\square$ Eu não consigo fazer nenhum tipo de trabalho.

Seção 8 - Dirigir automóveis

$\square$ Eu posso dirigir meu carro sem nenhuma dor no pescoço.

- Eu posso dirigir meu carro tanto quanto eu queira com uma dor leve no pescoço.

$\square$ Eu posso dirigir meu carro tanto quanto eu queira com uma dor moderada no pescoço.

$\square$ Eu não posso dirigir meu carro tanto quanto eu queira por causa de uma dor moderada no meu pescoço.

$\square$ Eu não posso dirigir meu carro por causa de uma dor forte no meu pescoço.

$\square$ Eu não posso dirigir meu carro e maneira nenhuma.

$\square$ Pergunta não se aplica por não saber dirigir ou não dirigir muitas vezes. 
Seção 9 - Dormir

$\square$ Eu não tenho problemas para dormir.

$\square$ Meu sono é um pouco perturbado (menos de 1 hora sem conseguir)

$\square$ Meu sono é um levemente perturbado (1 - 2 horas sem conseguir dormir)

$\square$ Meu sono é moderadamente perturbado (2 - 3 horas sem conseguir dormir)

Meu sono é muito perturbado (3 - 5 horas sem conseguir dormir)

- Meu sono é completamente perturbado (1 -2 horas sem sono)

Seção 10 - Diversão

$\square$ Eu consigo fazer todas as minhas atividades de diversão sem nenhuma dor no pescoço.

$\square$ Eu consigo fazer todas as minhas atividades de diversão com alguma dor no pescoço.

- Eu consigo fazer a maioria, mas não todas as minhas atividades de diversão, por causa da dor no meu pescoço.

$\square$ Eu consigo fazer poucas das minhas atividades de diversão por causa da dor no meu pescoço.

$\square$ Eu mal consigo fazer quaisquer atividades de diversão por causa da dor no meu pescoço

$\square$ Eu não consigo fazer nenhuma atividade de diversão.

Score: [50] (100\%)

Data: 


\section{ANEXO 4}

Escala de Pensamento Catastrófico sobre a Dor (B-PCS)

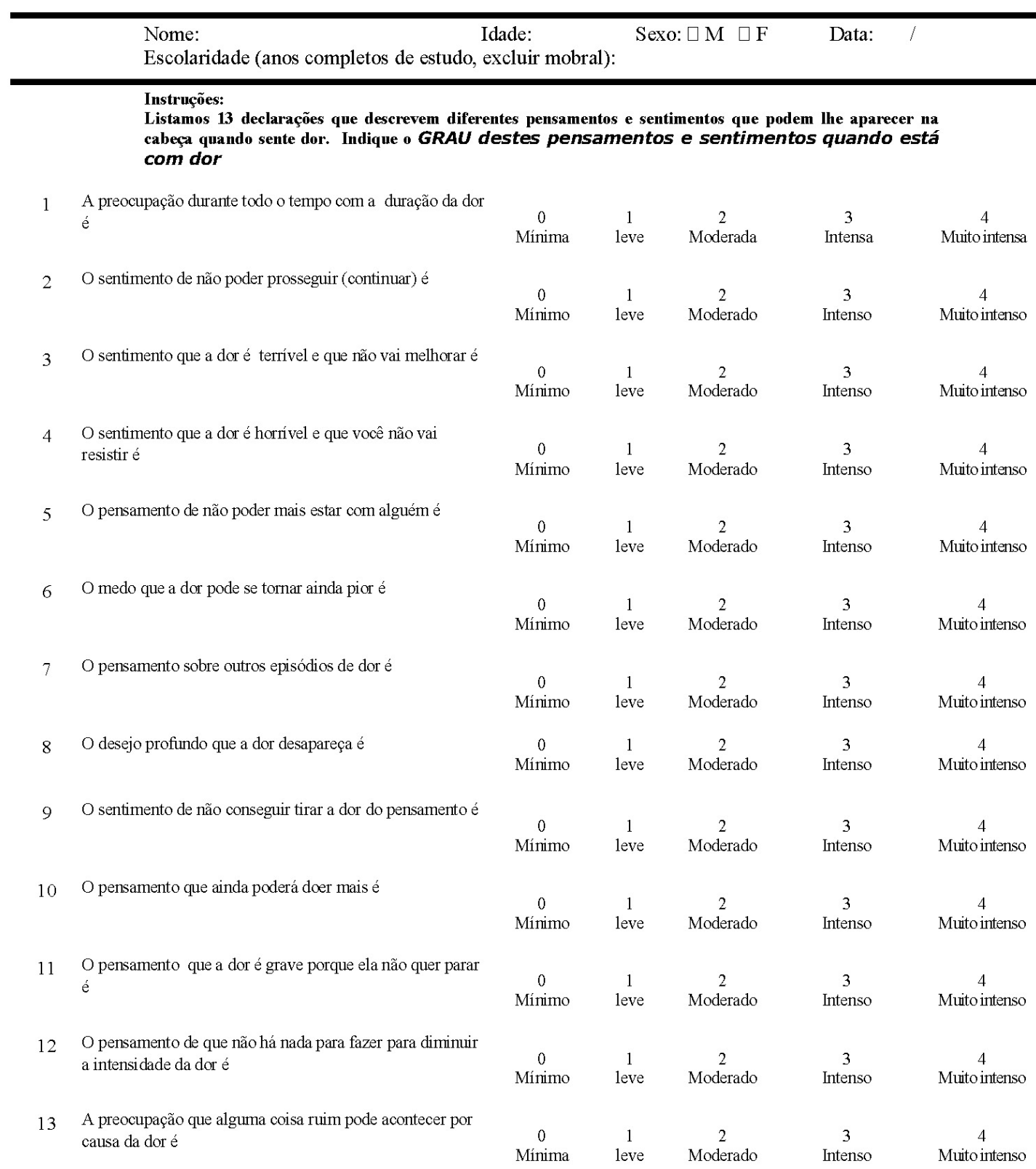




\section{ANEXO 5}

Testes Quantitativos Sensoriais

\section{MDT}

\begin{tabular}{|c|c|c|c|c|c|c|c|c|c|c|c|}
\hline $\begin{array}{l}\text { Estimulo } \\
\text { inicial. }\end{array}$ & + & - & + & - & + & - & + & - & + & - & Média \\
\hline & & & & & & & & & & & \\
\hline & & & & & & & & & & & \\
\hline
\end{tabular}

2. MPT

Baseline

\begin{tabular}{|c|c|c|c|c|c|c|c|c|c|c|c|}
\hline $\begin{array}{l}\text { Estimulo } \\
\text { inicial }\end{array}$ & + & - & + & 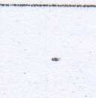 & + & - & + & - & + & - & Média \\
\hline & & & & & & & & & & & \\
\hline & & & & & & & & & & & \\
\hline
\end{tabular}

